\title{
Simultaneous detection of monacolins and citrinin of angkak produced by Monascus purpureus strains using Liquid Chromatography-Mass Spectrometry (LC-MS/MS)
}

\author{
${ }^{1,2}$ Sulandari, L., ${ }^{2,3}$ Utami, T., ${ }^{2}$ Hidayat, C. and ${ }^{2,3, *}$ Rahayu, E.S. \\ ${ }^{1}$ Department of Home Economics, Engineering Faculty, Universitas Negeri Surabaya \\ Jl. Ketintang, Surabaya 60231, Indonesia \\ ${ }^{2}$ Department of Food and Agricultural Product Technology, Faculty of Agricultural Technology, \\ Universitas Gadjah Mada, Jl. Flora No.1 Bulaksumur, Yogyakarta 55281, Indonesia \\ ${ }^{3}$ Center for Food and Nutrition Studies, Universitas Gadjah Mada, Jl. Teknika Utara, Sleman, \\ Yogyakarta 55281, Indonesia
}

\author{
Article history: \\ Received: 7 July 2020 \\ Received in revised form: 17 \\ August 2020 \\ Accepted: 27 September \\ 2020 \\ Available Online: 31 January \\ 2021
}

\section{Keywords:}

Angkak,

Citrinin,

LC-MS/MS,

Monacolin K,

Monascus purpureus

DOI:

https://doi.org/10.26656/fr.2017.5(1).333

\begin{abstract}
Angkak or red mold rice is produced from the fermentation of white rice using Monascus purpureus, which results in the red color of the fermented rice. Angkak has been used as a natural coloring agent for food, spices, and medicine. The active compound in angkak that contributes to lower blood cholesterol is known as monacolin (monacolin K). However, the presence of citrinin, the byproduct of angkak fermentation, needs to be considered as it can cause hepato-nephrotoxic mycotoxin. The contents of pigments, monacolins, and citrinin as secondary metabolites depends on the Monascus strain and fermentation conditions. This study aims to analyze simultaneously monacolins and citrinin in angkak produced by M. purpureus strains using Liquid Chromatography-Mass Spectrometry (LCMS/MS). The angkak was prepared by fermentation using M. purpureus FNCC 6008 and M. purpureus JK2. A total of $10^{7} M$. purpureus spores $/ \mathrm{mL}$ was inoculated into the rice. The fermentation was carried out at room temperature $\left(25-30^{\circ} \mathrm{C}\right)$ for 14 days. The detection using LC-MS/MS showed that the monacolin $\mathrm{K}$ in angkak from both strains was below LOQ ( $<$ limit of quantification). The analysis of citrinin content in angkak showed that JK2 strain produced lower citrinin $(1.10 \pm 0.021 \mu \mathrm{g} / \mathrm{g})$ compared to FNCC 6008 $(3.01 \pm 0.072 \mu \mathrm{g} / \mathrm{g})$. The other monacolins found in angkak from both strains were including dehydromonacolin $\mathrm{K}$, monacolin $\mathrm{J}$ (qualitative), and mevastatin. Based on t-test, the amount of both mevastatin and citrinin in angkak produced by two different strains were significantly different. In contrast, the amount of dehydromonacolin $\mathrm{K}$ in both angkak was comparable. The simultaneous detection result of LC-MS/MS could determine the choice of Monascus strains quickly. JK2 strain was considered as safe, thus it could be chosen to be applied to food products.
\end{abstract}

\section{Introduction}

Angkak or red mold rice (RMR) is a product of $M$. purpureus fermentation via solid-state fermentation using rice as the primary media. There are many names to refer to angkak, in China and Taiwan angkak is called "Hong Qu", "Hon-Chi”, "Anka”, or "Ang-kak"; whereas the Japanese people use the name of "Beni Koji" or "red Koji". In America and Europe angkak is called as "red rice", "red mold rice" or "red Chinese rice". However, the name red yeast rice (RYR) is often used in many publications and commercial products even though it is not an appropriate name for filamentous fungi (Wang and Lin, 2007; Song et al., 2019).

Monascus can produce beneficial secondary metabolites, such as pigments (food-grade colorants), monacolins (cholesterol-lowering agents), $\gamma$-butyric acid (an antihypertensive substance), dimerumic acid (an antioxidant) (Chung et al., 2009, Chen et al., 2015; Song et al., 2019). The red pigment of angkak is mainly used as a natural coloring for food, but it can also be used as a preservative in meat and fish products (Wang and Lin, 2007; Chen et al., 2015), cheese (Devi and Meera, 2015) as well as an agent to increase platelets in dengue hemorrhagic fever (Danuri, 2008; Ristiarini et al., 
2017a). Monacolins can be used as a cholesterollowering agent (Campbell and Vederas, 2010; Heinz et al., 2016) by inhibiting the enzyme of hydroxymethylglutaryl coenzyme A (HMG-CoA) reductase in cholesterol biosynthesis (Song et al., 2012; Heinz et al., 2016). Approximately 14 structural forms of monacolin have been identified from the genus of Monascus, namely: monacolin K (monacolin K lactone form; monacolin $\mathrm{K}$ acid form), monacolin $\mathrm{J}$, monacolin $\mathrm{J}$ acid form, monacolin $\mathrm{L}$, monacolin $\mathrm{L}$ acid form, monacolin $\mathrm{M}$, monacolin $\mathrm{M}$ acid form, monacolin $\mathrm{X}$, monacolin $\mathrm{X}$ acid form, and dehydromonacolin $\mathrm{K}$, dihydromonacolin L, compactin, $3 \alpha$ hydroxy 3,5 dihydromonacolin L (Li et al., 2004; Avula et al., 2014).

Citrinin was reportedly detected in various $M$. purpureus fermented products (Vuković et al., 2017). Citrinin, a mycotoxin which has harmful effects on the function and structure of the kidney and is able to modify liver metabolism (Mornar et al., 2013; Ji et al., 2015). The maximum level of citrinin in red yeast rice-based food supplements is $2000 \mu \mathrm{g} / \mathrm{kg}$ ( $2 \mathrm{ppm}$ ) (Commission Regulation (EU) No 212/2014 of 6 March 2014). The presence of citrinin in food products needs to be considered to ensure product safety.

The content of secondary metabolites of angkak depends on the Monascus strain and fermentation conditions. Detection of the amount of monacolin K and citrinin has been carried out on various Monascus fermented products in the form of angkak and food supplements. Detection of monacolin K (Li et al., 2004; Song, et al., 2012; Di Donna et al., 2018) and citrinin (Ji et al., 2015; Vuković et al., 2017; Vuković et al., 2019) can be carried out individually or simultaneously (Nigović et al., 2013; Mornar et al., 2013; Avula et al., 2014). Chromatographic techniques are often used in the detection of monacolin $\mathrm{K}$ and/or citrinin (Avula et al., 2014). Although the chromatographic technique is sensitive and selective (Nigovicet al., 2013), it is time-consuming and requires expensive equipment and solvents. Chromatographic techniques that have been developed to simultaneously detect monacolin $\mathrm{K}$ and citrinin that are fast and accurate include: chromatography electromagnetic capillary chromatography (Nigovicet al., 2013), liquid chromatography with array diode detectors (DAD) and/ or with mass spectrometry (MS) (Mornar et al., 2013) and liquid chromatography-DAD-QtoF-MS (Avula et al., 2014).

Fast detection of monacolin $\mathrm{K}$ and/or citrinin in Monascus fermentation products have been carried out for screening products from adulteration, including labels that do not match the contents of product (Li et al.,
2004; Song et al., 2012, Monar et al., 2013; Avula et al., 2014; Di Donna et al., 2018; Vuković et al., 2019). Simultaneous detection of monacolin $\mathrm{K}$ and citrinin of angkak produced by $M$. purpureus strains has not been widely reported. This study aimed to analyze simultaneously monacolins and citrinin in angkak produced by $M$. purpureus strains using Liquid Chromatography-Mass Spectrometry (LC-MS/MS).

\section{Materials and methods}

\subsection{Microorganism}

There were three strains of $M$. purpureus used in this study. The strain of $M$. purpureus FNCC 6008 was purchased from the collection of Food and Nutrition Collection Center (FNCC), Universitas Gadjah Mada Indonesia; M. purpureus JK2 strain was obtained from Widya Mandala University, Surabaya, Indonesia that was isolated from angkak at a pharmacy shop in Jakarta; and M. purpureus HD-CC 001 was obtained from the collection of Microbiology Laboratory, School of Pharmacy, Bandung Institute of Technology. The culture strains were inoculated into potato dextrose agar (PDA; Merck) slants, and then incubated at room temperature $\left(25-30^{\circ} \mathrm{C}\right)$ for 14 days. Spore suspensions were prepared by the addition of sterilized water into the grown culture on PDA agar slant. The spore concentration was $10^{7}$ spores per $\mathrm{mL}$ as counted by using haemocytometer.

\subsection{Solid-state fermentation}

Solid-state fermentation was conducted by inoculating M. purpureus culture into the rice. The IR 64 rice was purchased from Giant supermarket in Yogyakarta. The rice was soaked in water (1:1) for 24 hours. After soaking the rice was rinsed and drained. A total of $100 \mathrm{~g}$ of rice was put into a $500 \mathrm{~mL}$ erlenmeyer and sterilized at $121^{\circ} \mathrm{C}$ for 15 mins and then cooled to room temperature. The sterilized rice was inoculated with $10 \mathrm{~mL}$ spore suspension of M. purpureus $\left(10^{7}\right.$ spores/ $\mathrm{mL}$ ). After cultivation at room temperature (25$30^{\circ} \mathrm{C}$ ) for 14 days, the angkak (fermented rice) was dried with cabinet dryer at $40^{\circ} \mathrm{C}$ for 5 hours (until the final moisture content of less than $10 \%$ was achieved). The dried angkak was blended to a fine powder before extraction.

\subsection{Chemicals}

Monacolin K (lovastatin) and citrinin standard were ordered from Sigma-Aldric RTC, WY, USA. Acetonitrile gradient grade and formic acid were purchased from Germany. Water used from the purification process (Evoqua) 


\subsection{Sample extraction}

The sample extraction and analysis using LC-MS/ MS followed Avula et al. (2014) and Di Dona et al. (2018) with modification. Approximately $0.04 \mathrm{~g}$ of angkak powder was extracted using $10 \mathrm{~mL}$ of acetonitrile in a sonicator (Branson 2200 , USA) at $30^{\circ} \mathrm{C}$ for 30 mins. The obtained mixture was heated with a waterbath at $60^{\circ}$ $\mathrm{C}$ for $1 \mathrm{hr}$ and then centrifuged (Zenith Lab, LC-04S, China) at $3500 \mathrm{rpm}$ for $10 \mathrm{~min}$. The amount of $0.01 \mathrm{~g}$ adsorbent (MgSO4: Na-Acetate, modification) was added into $1 \mathrm{~mL}$ supernatant and then centrifuged (Hitachi, Japan) at $10000 \mathrm{rpm}$ for 5 mins. It was followed by filtration through nylon $0.2 \mu \mathrm{m}$ (Agilent, USA). The filtrate $(2 \mu \mathrm{L})$ was injected into the LC-MS/ MS.

\subsection{Mass spectrometry condition}

The sample analysis was carried out using LC-MS/ MS, Thermo Scientific UHPLC instrument, Accela LC type 1250 (Thermo Fisher Scientific, USA). The chromatographic separation used Hypersil Gold $(50 \mathrm{~mm}$ x $2.1 \mathrm{~mm}$ x $1.9 \mu \mathrm{m}$ ) column. Solvent A consisted of $0.1 \%$ formic acid in aquabidest and solvent $\mathrm{B}$ consisted of $0.1 \%$ formic acid in acetonitrile. The flow rate was set at $300 \mu 1 / \mathrm{min}$ and the sample injection volume was $2 \mu 1$. The linear gradient with the adjustment of the mobile phase was as follows: 0-0.6 $\mathrm{min}, 75 \% \mathrm{~A}$; 0.6-3.0 $\mathrm{min}$, $90 \% \mathrm{~B}$; 3.0-4.0 min, $90 \% \mathrm{~B}$; 4.0-4.5 min, $25 \% \mathrm{~B}$ and 4.5 $-6.0 \mathrm{~min}, 75 \% \mathrm{~A}$. The column was setat $30^{\circ} \mathrm{C}$, and the autosampler compartment was set to $16^{\circ} \mathrm{C}$.

The use of MS/MS Triple Q (quadrupole) TSQ Quantum Access Max mass spectrometers from Thermo Finnigan with ESI (electrospray ionization) as ion sources was controlled by TSQ Tune software which was operated in a positive ion mode. ESI ionization conditions were adjusted as following: $3 \mathrm{kV}$ spray voltage; evaporation temperature, $300^{\circ} \mathrm{C}$; capillary temperature, $300^{\circ} \mathrm{C}$; nitrogen as a sheath gas pressure, 40 psi; and Aux gas pressure, 10 psi with argon gas. Determination of quantity used the SRM (selected reaction monitoring) method. Monacolin $\mathrm{K}$ molecules were adjusted with precursor ions $(\mathrm{m} / \mathrm{z}) 405$, and product ion $(\mathrm{m} / \mathrm{z}) 199$ while the citrinin was adjusted with precursor ion $(\mathrm{m} / \mathrm{z}) 251$, and the product ion $(\mathrm{m} / \mathrm{z}) 233$.

\subsection{Color measurement}

Color measurement was conducted using chromameter CR 400 (Konica Minolta Co. Ltd., Osaka, Japan). White calibration using the white calibration plate was done before measuring. The ground samples (angkak) were poured in a cuvette. The measurement button was pressed after making sure the ready lamp ON. Measurement was done, and the data was displayed. The measurement was expressed in three parameters of $\mathrm{L}^{*}$, $a^{*}$ value, and $b^{*}$ value. The $L^{*}$ value is a lightness variable which has a value from 0 (black) to 100 (white). The $\mathrm{a}^{*}$ indicates redness (+ value) or greenness (- value), whereas $b^{*}$ indicates yellowness (+ value) or blueness (value).

\subsection{Statistical analysis}

The results were statistically analyzed using ttest.The statistical product and service solution (SPPS) statistical software version 22 was used for statistical analysis.

\section{Results and discussion}

\subsection{Growth of Monascus purpureus in PDA medium}

M. purpureus spore was grown on PDA medium and it germinated to form branched hyphae. A mass of hyphae is termed mycelium (Manan et al., 2017). In this study, the color development of 3 strains $M$.

Table 1. The color change of M. purpureus in PDA medium during incubation at room temperature $\left(25-30^{\circ} \mathrm{C}\right)$ for 14 days

\begin{tabular}{ccccc}
\hline Incubation & \multirow{2}{*}{ (days) } & Colony color & \multicolumn{3}{c}{ Strain } \\
\cline { 3 - 5 } & & FNCC 6008 & JK2 & HD-CC 001 \\
\hline 1 & White & + & + & + \\
2 & White & ++ & ++ & + \\
3 & White & ++ & ++ & + \\
4 & White-yellowish & +++ & +++ & + \\
5 & White-yellowish & +++ & +++ & + \\
6 & White-yellowish & ++++ & ++++ & + \\
7 & Orange & ++++ & +++++ & + \\
8 & Orange & +++++ & +++++ & + \\
9 & Rich orange & +++++ & +++++ & + \\
10 & Rich orange & +++++ & ++++++ & + \\
11 & Orange-red & ++++++ & ++++++ & + \\
12 & Orang-red & ++++++ & ++++++ & ++ \\
13 & Rich red & ++++ & +++++++ & - \\
14 & Rich red & ++++ & +++++++ & - \\
\hline
\end{tabular}

+: few; ++: medium; +++: many; ++++ : numerous 
purpureus mycelium that incubated in PDA medium at room temperature $\left(25-30^{\circ} \mathrm{C}\right)$ for 14 days was visually observed (Table 1). In the early stages of growth, mycelium was white, then it changed to vibrant orange and finally became red. The color development of M. purpureus mycelium followed Danuri (2008).

At the early stage, the colony was observed having white color until the third day of incubation. On the fourth day of incubation, the color production started and continued to increase along with incubation period (Dikshit and Tallapragada, 2011). However, this rapidly changedinto a vibrant orange (8-9 days) and later to a distinctly rich red color (14-16 days) (Manan et al., 2017; Tallapragada et al., 2017).

The strain of $M$. purpureus FNCC 6008 and JK2 produced yellow, orange, and red pigments with the red pigment being predominant. The red pigment of JK2 was stronger than that of FNCC 6008 at the final stage (14 days). The HD-CC 001 strain produced mycelium which was still white until incubation for 14 days, even though the closest part to the PDA medium appeared orange-red. The final color of 3 strains $M$. purpureus mycelium on

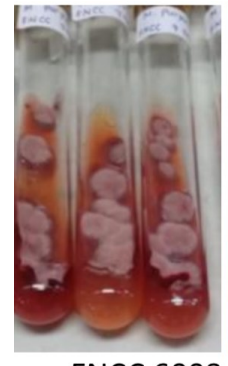

a. FNCC 6008

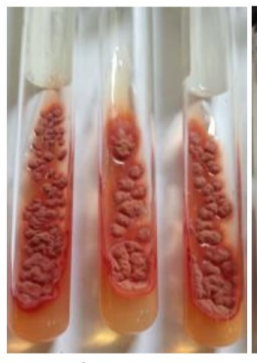

b. JK2

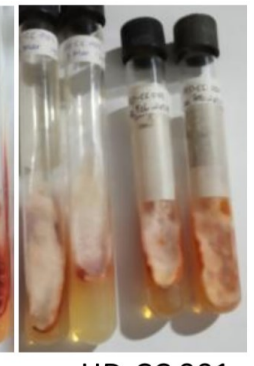

c. HD-CC 001

Figure 1. The mycelium pigment of $M$. purpureus strains FNCC 6008, JK2 and HD-CC 001 in PDA medium at room temperature $\left(25-30^{\circ} \mathrm{C}\right)$ for 14 days incubation

14 days of incubation as shown in Figure 1.

The above result indicated that pigment production of HD-CC 001 strain was lower than strains FNCC 6008 and JK2. It was shown that pigment production depended on the strain. In the following part of the study, the strains FNCC 6008 and JK2 were used to produce angkak with rice as the substrate.

\subsection{Solid-state fermentation}

M. purpureus strains FNCC 6008 and JK2 was cultivated on sterilized rice at room temperature for 14 days. Based on the produced angkak, it could be visually observed that the JK2 strain gave more red pigment than FNCC 6008 strain (Figure 2). The starch content in the rice was the major carbon source during the growth of M. purpureus. Yang et al. (2015) reported that in rice medium, the biomass of $M$. purpureus increased rapidly during the first stage of the logarithmic growth phase (approximately on the $4^{\text {th }}$ day), and the synthesis of pigment occurred rapidly in the near end of the

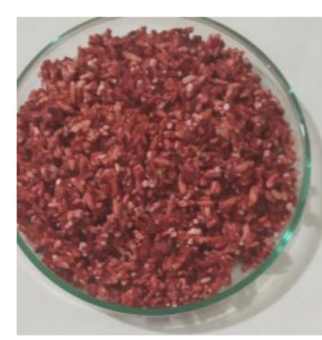

a

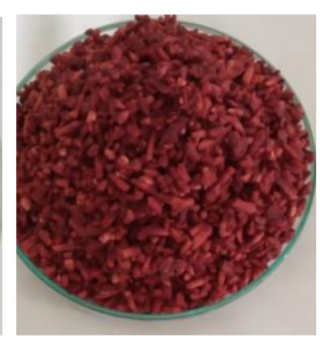

b
Figure 2. Angkak fermented by M. purpureus strains: a. FNCC 6008 ; b. JK2 at room temperature $\left(25-30^{\circ} \mathrm{C}\right)$ for 14 days incubation

logarithmic growth phase (approximately on the $8^{\text {th }}$ day).

The differences in the color of angkak indicated the differences in pigment synthesis during fermentation (Table 2). Significant differences were found in lightness $\left(\mathrm{L}^{*}\right)$, yellowness $\left(\mathrm{b}^{*}\right)$, and redness $\left(\mathrm{a}^{*}\right)$ of angkak. Angkak fermented by FNCC 6008 possessed higher lightness $\left(\mathrm{L}^{*}\right)$ and yellowness $\left(\mathrm{b}^{*}\right)$, whereas angkak fermented by JK2 had higher redness $\left(\mathrm{a}^{*}\right)$. The high value of lightness and yellowness, as well as the low redness, resulted in a pale red of angkak. In contrast, the low value of lightness and yellowness, as well as the high redness, showed an intense red of angkak (Ristiarini et al., 2017b). Angkak fermented by JK2 was significantly red $(24.05 \pm 0.028$ vs. $15.14 \pm 0.104, \mathrm{P}=$ 0.000).

Table 2. Color value $\mathrm{L}^{*}, \mathrm{a}^{*}, \mathrm{~b}^{*}$ of angkak fermented by $M$. purpureus strain FNCC 6008 and JK2 at room temperature (25 $-30^{\circ} \mathrm{C}$ ) for 14 days incubation

\begin{tabular}{cccc}
\hline Variable & FNCC 6008 & JK2 & P-value \\
\hline L* $^{*}$ & $71.54 \pm 0.534$ & $56.74 \pm 0.284$ & 0 \\
$\mathrm{a}^{*}$ & $15.14 \pm 0.104$ & $24.05 \pm 0.028$ & 0 \\
$\mathrm{~b}^{*}$ & $19.25 \pm 0.182$ & $17.91 \pm 0.123$ & 0 \\
\hline
\end{tabular}

The difference in the color of angkak produced by the strains of FNCC 6008 and JK2 was associated with the differences in the ability to utilize glucose from glycolysis. Therefore, it affected the availability of acetyl -CoA, which could have an impact on the formation of secondary metabolites, including pigment production. On the eight days of fermentation, it was clear that the expression of acetyl-CoA carboxylase converts acetyl$\mathrm{CoA}$ into malonyl-CoA, as a precursor of pigment synthesis. Increased formation of malonyl-CoA and less use of malonyl-CoA for fatty acid biosynthesis can provide more malonyl-CoA precursors for pigment biosynthesis (Yang et al., 2015).

Based on the previous reports, M. purpureus pigment biosynthesis involves two synthesis pathways, namely the polyketide pathway and the fatty acid pathway. 
Pigment formation starts from the formation of chromophore hexaketide derived from 1 mole of acetate with 5 moles of malonate by the enzyme polyketide synthase through the polyketide pathway. Simultaneously, through the biosynthetic pathway of fatty acids, the medium-chain fatty acid, such as octanoic acid forms B-keto acids. Beta-keto acids bind to the chromophore structure through trans-esterification reactions to form monascorubrin orange pigments (or rubropunctatin by binding with hexanoic acid). The reduction of monascorubrin orange pigment forms ankaflavin yellow pigment (or monascin from rubropunctatin). The amination reaction of the orange pigment (monascorubrin) with $\mathrm{NH}_{3}$ derived from glutamic acid forms a red color (monascorubramine and rubropunctamine) (Hajjaj et al., 2000; Chen et al., 2015).

\subsection{Monacolins and Citrinin Detection by LC-MS/MS}

Detection of monacolin $\mathrm{K}$ and citrinin content in angkak powder fermented by FNCC 6008 and JK2 was carried out using LC-MS/MS. The monacolin $\mathrm{K}(\mathrm{m} / \mathrm{z}$ $405)$ and citrinin $(\mathrm{m} / \mathrm{z} 251)$ in angkak were identified by comparing the chromatograms obtained from both samples with the chromatograms from the standard monacolin $\mathrm{K}$ and citrinin (Figure 3). Using the LC-MS/ MS, various compounds such as dehydromonacolin $\mathrm{K}$ (m/z 387), mevastatin (compactin $\mathrm{m} / \mathrm{z}$ 391), monacolin J $(\mathrm{m} / \mathrm{z}$ 321, qualitative) (Avula et al., 2014) were also detected in both angkak powder samples. The number of various compounds detected by LC-MS/MS was shown in Table 3. Detection of several compounds with a single run at the same time requires a smaller number of samples and solvents, shorter time, and more sensitive high resolution (Monar et al., 2013). LC-MS/MS method obtains a high concentration of analytes (Song et al., 2012), informative detection (Ajdari et al., 2011) and provides very high sensitivity and accuracy (Vuković et al., 2019). The detection of specificity was determined by mass spectrometry (Avula et al., 2014; Di Dona et al., 2018).

As shown in Table 3, the angkak powder produced with FNCC 6008 and JK2 had a low content of monacolin $\mathrm{K}$, as the analysis using LC-MS/MS showed that the monacolin $\mathrm{K}$ from both samples were under the limit of quantification $(<\mathrm{LOQ})$. This indicated that the ability of both strains in synthesizing monacolin $\mathrm{K}$ was low. Monacolin K level of various M. purpureus strain in rice medium that analyzed by LC-MS/MS was vary in amount, NTU 601 produces $530 \pm 32(\mu \mathrm{g} / \mathrm{g})$, BCRC 31499 produces $119 \pm 21(\mu \mathrm{g} / \mathrm{g})$ (Lee et al., 2006), while angkak using FTC5391 did not contain monacolin K (Adjari et al., 2011).

The monacolin $\mathrm{K}$ was converted into dehydromonacolin $\mathrm{K}$ via dehydration, during storage. It eliminates the therapeutic effects of monacolin $\mathrm{K}$ (Jirasatid et al., 2013). The amount of dehydromonacolin $\mathrm{K}$ in both angkak was not significantly different. JK2 strain was able to produce higher mevastatin than FNCC 6008. Considering its structure and biosynthesis, the mevastatin or ML-236A or known as compactin, is similar to lovastatin (monacolin K). It also acts as an inhibitor of HMG-CoA and is highly effective in lowering plasma cholesterol levels in animals and man

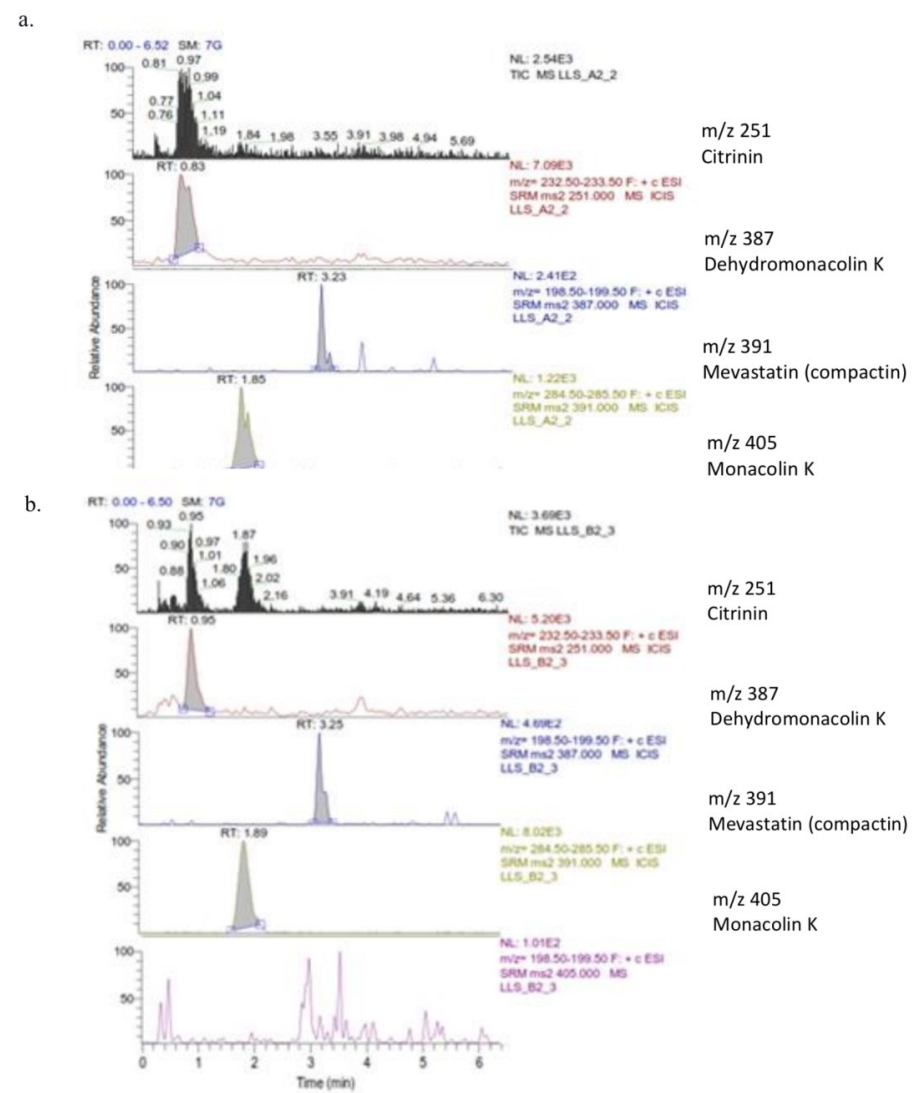

Figure 3. Chromatograms of angkak fermented by $M$. purpureus strains: a. FNCC 6008; b. JK2

Table 3. Quantitative analysis of angkak fermented by $M$. purpureus strain FNCC 6008 and JK2 at room temperature (25 $-30^{\circ} \mathrm{C}$ ) for 14 days incubation using LC-MS/MS

\begin{tabular}{cccc}
\hline Compounds $(\mu \mathrm{g} / \mathrm{g})$ & FNCC 6008 & JK2 & P-value \\
\hline Monacolin K & $<$ LOQ & $<$ LOQ & - \\
Dehydromonacolin K & $74.62 \pm 2.161$ & $71.82 \pm 1.245$ & 0.14 \\
Mevastatin & $86.60 \pm 2.753$ & $183.26 \pm 1.108$ & 0 \\
Citrinin & $3.01 \pm 0.072$ & $1.10 \pm 0.021$ & 0 \\
\hline
\end{tabular}

(Endo et al., 1985; Campbell and Vederas, 2010).

Analysis of the citrinin concentration in angkak powder showed that the strain JK2 produced lower concentration of citrinin $(1.10 \pm 0.021 \mu \mathrm{g} / \mathrm{g})$ compared to the strain FNCC $6008(3.01 \pm 0.072 \mu \mathrm{g} / \mathrm{g})$. The citrinin concentration in both samples was significantly different. Lee et al. (2007) reported that M. purpureus NTU 568 produce citrinin in angkak $1.89 \mathrm{ppm}$, NTU $6010.46 \mathrm{ppm}$ and NTU $3010.37 \mathrm{ppm}$, while strain TISTR3541 
produce citrinin $0.26 \mathrm{ppm}$ (Adjari et al., 2011), it was detected by LC-MS/MS. Ristiarini et al. (2017b) reported the citrinin content of the commercial angkak from several region in Indonesia ranged from $17.94 \mathrm{ppm}$ to $142.74 \mathrm{ppm}$.

The citrinin concentration in angkak fermented by $M$. purpureus JK2 strain was under the maximum level of citrinin allowed in foods based on the fermented rice with M. purpureus according to EU 212/2014 (2000 $\mu \mathrm{g} / \mathrm{kg}$ or $2 \mu \mathrm{g} / \mathrm{g}$ ). Although Lee et al. (2010) reported that the concentration of $200 \mathrm{ppm}$ citrinin in a Monascus fermentation product did not affect liver and kidney function as well as cause nephrotoxicity and hepatotoxicity in the animal test using rat, citrinin concentration of $2 \mathrm{ppm}(2 \mu \mathrm{g} / \mathrm{g})$ was considered as a safe concentration. Therefore, the JK2 strain was considered as safe to be chosen and applied to food production.

\section{Conclusion}

The simultaneous detection of monacolin $\mathrm{K}$ and citrinin on angkak using LC-MS/MS was able to be carried out quickly. In addition, LC-MS/MS could be used to detect other monacolins. The M. purpureus strain JK2 produced citrinin lower than FNCC 6008, so it was preferable considering the safety aspect. However, the ability of both strains to produce monacolin $\mathrm{K}$ was still very low.

\section{Conflict of interest}

The authors declare no conflict of interest.

\section{Acknowledgments}

Theresearch work was funded by Indonesia Endowment Fund for Education, The Indonesian Ministry of Finance (BUDI-DN LPDP). The authors are very grateful to Dr Susana Ristiarini (Widya Mandala University, Surabaya, Indonesia), Marlia Singgih, PhD (Microbiology Laboratory, School of Pharmacy, Bandung Institute of Technology, Indonesia) and Dr Anna Yuliana (Department of Pharmacy, STKes Bakti Tunas Husada Tasikmalaya, West Java, Indonesia) for providing $M$. purpureus strains, as well as Fathyah Hanum Pamungkaningtyas, MSc. for helpful preparing manuscript.

\section{References}

Ajdari, Z., Ebrahimpour, A., Abdul Manan, M., Hamid, M., Mohamad, R. and Ariff, A.B. (2011). Assessment of monacolin in the fermented products using Monascus purpureus FTC5391. Journal of Biomedicine and Biotechnology, 2011, 426168. https://doi.org/10.1155/2011/426168

Avula, B., Cohen, P.A., Wang, Y.H., Sagi, S., Feng, W., Wang, M., Zweigenbaum, J., Shuangcheng, M. and Khan, I.A. (2014). Chemical profiling andquantification of monacolins and citrinin in red yeast rice commercial raw materials and dietary supplements using liquid chromatography-accurate QToF mass spectrometry: Chemometrics application. Journal of Pharmaceutical and Biomedical Analysis, 100, 243-253. https:// doi.org/10.1016/j.jpba.2014.07.039

Campbell, C.D. and Vederas, J.C. (2010). Biosynthesis of lovastatin and related metabolites formed by biosynthesis of lovastatin and related metabolites formed by fungal iterative PKS enzymes. Biopolymers, 93(9), 755-763. https:// doi.org/10.1002/bip.21428

Chen, W., He, Y., Zhou, Y., Shao, Y., Feng, Y., Li, M. and Chen, F. (2015). Edible filamentous fungi from the species Monascus: early traditional fermentations, modern molecular biology, and future genomics. Comprehensive Reviews in Food Science and Food Safety, 14(5), 555-567. https:// doi.org/10.1111/1541-4337.12145

Chung, C.C., Huang, T.C. and Chen, H.H. (2009). The optimization of Monascus fermentation process for pigments increment and citrinin reduction, presented at 2009 Ninth IEEE International Conference on Bioinformatics and Bioengineering, Taichung City, 2009. New York, NY: IEEE. https://doi.org/10.1109/ BIBE.2009.33

Commission Regulation (EU) No 212/2014. (2014). 6 March 2014 amending Regulation (EC) No $1881 / 2006$ as regards maximum levels of the contaminant citrinin in food supplements based on rice fermented with red yeast Monascus purpureus. Official Journal of the European Union. Retrieved on 26 June, 2020 from http://extwprlegs1.fao.org/docs/ pdf/eur131703.pdf

Danuri, H. (2008). Optimizing angkak pigments and lovastatin production by Monascus purpureus. Hayati Journal of Biosciences, 15(2), 61-66. https:// doi.org/10.4308/hjb.15.2.61

Devi, C.A. and Meera, J. (2015). Identification, mass production and application of pigment in food industry isolated from Monascus sp. International Journal of Bio-Technology and Research, 5(4), 1-10.

Di Donna, L., Bartella, L., Napoli, A., Sindona, G. and Mazzotti, F. (2018). Assay of lovastatin containing dietary supplement by LC-MS/MS under MRM condition. Journal of Mass Spectrometry, 53(9), 811816. https://doi.org/10.1002/jms.4202 
Dikshit, R. and Tallapragada, P. (2011). Monascus purpureus: A potential source for natural pigment production. Journal of Microbiology and Biotechnology Research, 1(4), 164-174.

Endo, A., Negishi, Y., Iwashita, T., Mizukawa, K. and Hirama, M. (1985). Biosynthesis of ML-236B (compactin) and monacolin K. The Journal of Antibiotics, 38(3), 444-448. https://doi.org/10.7164/ antibiotics. 38.444

Hajjaj, H., Klaebe, A., Goma, G., Blanc, P.J., Barbier, E. and François, J. (2000). Medium-chain fatty acids affect citrinin production in then filamentous fungus Monascus ruber. Applied and Environmental Microbiology, 66(3), 1120-1125. https:// doi.org/10.1128/AEM.66.3.1120-1125.2000

Heinz, T., Schuchardt, J.P., Möller, K., Hadji, P. and Hahn, A. (2016). LDL-cholesterol-lowering effect of monacolin $\mathrm{K}$ from red yeast rice extract-results of a randomized, placebo-controlled intervention study. Nutrition Research, 36(10), 1162-1170. https:// doi.org/10.1016/j.nutres.2016.07.005

Ji, X., Xu, J., Wang, X., Qi, P., Wei, W., Chen, X., Li, R. and Zhou, Y. (2015). Citrinin determination in red fermented rice products by optimized extraction method coupled to liquid chromatography tandem mass spectrometry (LC-MS/MS). Journal of Food Science, $\quad 80(6), \quad$ T1438-T1444. https:// doi.org/10.1111/1750-3841.12900

Jirasatid, S., Nopharatana, M., Kitsubun, P., Vichitsoonthonkul, T. and Tongta, A. (2013). Statistical optimization for monacolin $\mathrm{K}$ and yellow pigment production and citrinin reduction by Monascus purpureus in solid-state fermentation. Journal of Microbiology and Biotechnology,23(3), 364-374. https://doi.org/10.4014/jmb.1206.06068

Lee, C.L., Wang, J.J., Kuo, S.L. and Pan, T.M. (2006). Monascus fermentation of dioscorea for increasing the production of cholesterol-lowering agentmonacolin $\mathrm{K}$ and antiinflammation agent-monascin. Applied Microbiology and Biotechnology, 72, 1254 1262. https://doi.org/10.1007/s00253-006-0404-8

Lee, C.L., Hung, H.K., Wang, J.J. and Pan, T.M. (2007). Improving the ratio of monacolin $\mathrm{K}$ to citrinin production of Monascus purpureus NTU 568 under dioscorea medium through the mediation of $\mathrm{pH}$ value and ethanol addition. Journal of Agricultural and Food Chemistry, 55, 6493-6502. https:// doi.org/10.1021/jf0711946

Lee, C.H., Lee, C.L. and Pan, T.M. (2010). A 90-D toxicity study of Monascus-fermented products including high citrinin level. Journal of Food Science, 75(5), T91-T97. https://doi.org/10.1111/ j.1750-3841.2010.01626.x
Li, Y., Zhang, F., Wang, Z.T. and Hu, Z.B. (2004). Identification and chemical profiling of monacolins in red yeast rice using high-performance liquid chromatography with photodiode array detector and mass spectrometry. Journal of Pharmaceutical and Biomedical Analysis, 35, 1101-1112. https:// doi.org/10.1016/j.jpba.2004.04.004

Manan, M.A., Mohamad, R. and Ariff, A. (2017). The morphology and structure of red pigment producing fungus: Monascus purpureus. Journal of Microbiology and Experimentation, 5(1), 00138. https://doi.org/10.15406/jmen.2017.05.00138

Mornar, A., Sertić, M. and Nigović, B. (2013). Development of a rapid LC/DAD/FLD/MS ${ }^{\mathrm{n}}$ method for the simultaneous determination of monacolins and citrinin in red fermented rice products. Journal of Agricultural and Food Chemistry, 61(5), 10721080. https://doi.org/10.1021/jf304881g

Nigović, B., Sertić, M. and Mornar, A. (2013). Simultaneous determination of lovastatin and citrinin in red yeast rice supplements by micellar electrokinetic capillary chromatography. Food Chemistry, 138(1),531-538. https://doi.org/10.1016/ j.foodchem.2012.10.104

Ristiarini, S., Cahyanto, M.N., Widada, J. and Rahayu, E.S. (2017a). Citrinin and color analysis of angkak collected from several regions inIndonesia. Food Research,1(2), 43-49. https://doi.org/10.26656/ fr.2017.2.021

Ristiarini, S., Cahyanto, M.N., Widada, J. and Rahayu, E.S. (2017b). Identification of various colored Monascus sp and its biopigments and citrinin production in RMR. International Journal of Science and Research, 6(8), 1042-1046.

Song, F., El-Demerdash, A., Lee, S.J.S.H. and Smith, R.E. (2012). Fast screening of lovastatin in red yeast rice products by flow injection tandem mass spectrometry. Journal of Pharmaceutical and Biomedical Analysis, 57, 76-81. https:// doi.org/10.1016/j.jpba.2011.08.039

Song, J., Luo, J., Ma, Z., Sun, Q., Wu, C. and Li, X. (2019). Quality and authenticity control of functional red yeast rice-A review. Molecules, 24, 1944. https:// doi.org/10.3390/molecules24101944

Tallapragada, P., Dikshit, R., Phocas, M., Madhusudan, M.R. and Samprathi, S. (2017). Effect of amino acids on pigments, citrinin, and lovastatin production by Monascus purpureus under static conditions. Biologija, 63(2), 160-168. https://doi.org/10.6001/ biologija.v63i2.3527

Vuković, G.L., Bursić, V.P., Aleksić, G.A., Kuzmanović, S.T., Cara, M.X. and Abd, E.W.R.A. 
(2017). Data acquisition of triple quadrupole LC-MS for the citrinin determination. Matica Srpska Journal for Natural Sciences, 2017(133), 131-141. https:// doi.org/10.2298/ZMSPN1733131V

Vuković, G., Đukić, M., Bursić, V., Stojanović, T., Petrović, A., Kuzmanović, S. and Starović, M. (2019). Development and validation of LC-MS/MS method for the citrinin determination in red rice. Journal of Agronomy, Technology and Engineering Management,2(1), 192-199.

Wang, T.H. and Lin, T.F. (2007). Monascus Rice Products. In Taylor, S. (Ed). Advances in Food and Nutrition Research, vol. 53, p. 123-159. USA: Academic Press. https://doi.org/10.1016/S1043-4526 (07)53004-4

Yang, Y., Liu, B., Du, X., Li, P., Liang, B., Cheng, X., Du, L., Huang, D., Wang, L. and Wang, S. (2015). Complete genome sequence and transcriptomics analyses reveal pigment biosynthesis and regulatory mechanisms in an industrial strain, Monascus purpureus YY-1. Scientific Reports, 5(8331), 1-9. https://doi.org/10.1038/srep08331 